\title{
The Correlation of Self-Construal, Self-Efficacy, and Emotional Regulation Strategy as Cultural Factors with Social Anxiety: Preliminary Study
}

\author{
Cahyaning Suryaningrum \\ University of Muhammadiyah Malang \\ Doctoral Student at Gadjah Mada University \\ suryaningrumc@gmail.com
}

\begin{abstract}
The purpose of this preliminary study is to examine the correlation between self-construal, self-efficacy and emotion regulation strategies as cultural-related factors with social anxiety of college students in the context of collectivist societies (Indonesia). In addition, the present study investigates the development of level of social anxiety self-construal in them. This study was a quantitative-survey study with t-test and correlational analysis involving 116 undergraduate students as the research subjects. The results showed a significant correlation $(p<0.05)$ between interdependent self-construal with social anxiety, independent self-construal with self-efficacy and cognitive reappraisal strategy. Moreover, the result also indicated that college students' social anxiety level was high enough and the self-construal was more developed. The results of this preliminary study are expected to serve as a basis for building social anxiety model based on self-construal and intervention.
\end{abstract}

Keywords: Self-efficacy, social anxiety, self-construal, college students, emotion regulation strategies

\section{BACKGROUND}

Social anxiety is defined as the fear experienced by a person in social situations (performance and social interaction) that caused by negative evaluation from others. Social situations include performance situations such as speaking or performing in front others and meeting or having a conversation with unfamiliar people (APA, 2013). People who experience social anxiety often feel anxious to make mistakes and get embarrassed, afraid of being judged and rejected, and fear of ridicule. (Antony \& Swinson, 2008; APA, 2013; Henderson, Gilbert \& Zimbardo, 2014; McNeil \& Randall, 2014).

Basically, social anxiety in some degree is said to be normal, adaptive and is a positive response. However, if it often appears, it will cause a negative impact and become a problem. The impact of social anxiety may extend such as dropping out of school / college (APA, 2013; Topham \& Russell, 2012), perceiving poor academic performance (Levpusceek \& Berce, 2012); quality in raising opinions (Mesa, Beidel, \& Bunnel, 2014); academic adjustment in College (Nordstrom, Goguen, $\&$ Hiester, 2014); and affecting the quality of life (APA, 2013). Social anxiety can develop worse if it is left in long time without treatment (Antony \& Swinson, 2008).

Social anxiety can be experienced by anyone, including college students. A research conducted by Suryaningrum (2006) showed that among 211 college students of a University in Malang, $43.12 \%$ experienced social anxiety. The next study in 2014 indicated the result that among 120 college students, $42.5 \%$ is experiencing social anxiety (Suryaningrum, 2016). In 2015 , with 364 college students as subjects, the result indicated that $52.2 \%$ of them had low-moderate of social anxiety, while $24.7 \%$ is experiencing severe social anxiety (Suryaningrum, 2016).

In line with the findings, a research from Hasibuan, Srisayekti, and Moeliono (2015) with 255 college students in Bandung as subjects indicated that $20.9 \%$ had low-level of social anxiety, $47,8 \%$ at moderate level, and $31,2 \%$ at high category. In addition, Vriends, Pfaltz, Novianti and Hadiyono (2013) studied Swiss and Indonesian college students from a University in Yogyakarta and they found that Indonesian college students experience more social anxiety than Swiss college students with very significant differences.
The high cases of social anxiety among Indonesian college students, of course, should be a concern. It will influence the quality of Indonesian youth. College students are a generation that is prepared to become the nation's successor, which is expected to bring this nation toward the better changes and recognized by the world. Therefore, in addition to the quality of physical health, psychological and mental health of college students should also be a concern.

In line with the explanation above, understanding the factors contributing to the development of social anxiety becomes important to do as a basis for formulating intervention models. Many factors contribute to the development of social anxiety, either internal or external. The attention of the current researcher is to review social anxieties from cultural factors. From various studies, it is found that social anxiety in collectivist societies is almost always higher than in individualist societies (Essau, Leung, Conradt, Cheng, \& Wong, 2008; Heinrichs et al., 2006, Hong \& Woody, 2007; Hsu et al., 2012; Lee, Okazaki, \& Yoo; 2006; Pina, Little, Wynne, \& Beidel, 2014; Vriends et al., 2013; Woody, Miou, Kellman, \& Kellman-McFarlane, 2015). Some experts argue that discussing social anxiety is ultimately inseparable from social and cultural context (Hofmann, Asnaani, \& Hinton, 2010; Vriends et al., 2013; Woody et al., 2015; Zhu et al., 2014).

One of the cultural-related factors that also contributes to social anxiety is self-construal. Self-construal is defined as how individuals put themselves (self) in relation to others based on values and norms prevailing in the culture of society. Self-construal will affect psychological processes such as cognition, emotion, motivation, and behavior in the life of the individual (Markus \& Kitayama, 1991, 2010). There are two self-construal, namely interdependent selfconstrual and independent self-construal. Interdependent selfconstrual is more oriented towards placing individuals as part of others, adapting to the thoughts, feelings, actions of others, and displaying cautious behavior. Whereas independent selfconstrual is more emphasized to be an autonomous self, expresses the straightforwardness of thoughts, feelings, and actions alone, and prioritize success/achievement. In each person, there are two self-construal, though the more developed self-construal is influenced by the cultural background of the society (Markus \& Kitayama, 1991, 2010). 
The present research will examinethe development of selfconstrual of college students. When referring to the concepts of Markus and Kitayama (1991, 2010), the more developed is interdependent self-construal. However, this research hypothesized the opposite; the more developed self-construal in college students is independent self-construal. The reason is because the role and demands of college students. They adopt individualistic values such as emphasizing independence, freedom of expression, success, and achievement.

The studies that have been conducted in foreign countries almost always indicated that interdependent self-construal is positively correlated with social anxiety. Conversely, independent self-construal is negatively correlated with social anxiety (Levinson et al., 2011; Ho \& Lau, 2011; Hong \& Woody; 2007; Moscovith et al., 2005; Norasakkunkit et al., 2012; Park et al., 2011; Vriends et al., 2013). In Indonesia, studies of self-construal with social anxiety are limited. The study of cultural factors on social anxiety is relatively new and still developing (Schreier, 2010). It is, therefore, interesting to examine the relation of these two self-construal with social anxiety to the collectivist society in Indonesia.

Self-construal as a cultural-related factor also has an effect on the extent of self-efficacy and strategy in regulating emotions. Park et al. (2011) found that interdependent selfconstrual was positively associated with suppression, whereas independent self-construal was negatively correlated with suppression. People from collectivist societies are more likely to be suppressive (Butler, Lee \& Gross, 2007; De Leersnyder, Boiger \& Mesquita, 2013; Miyamoto \& Ma, 2014; Eng, 2012; Matsumoto, 2006). On the other hand, in terms of regulatory cognitive reappraisal strategy, it was found that the culture of individualism was higher in terms of cognitive reappraisal strategy (Matsumoto, Yoo, \& Nakagawa, 2008).

The development of one's self efficacy is also influenced by the underlying culture. Konnonovas and Dallas' (2009) study showed that there was a negative correlation between the values of collectivism and self-efficacy, and a positive correlation with the values of individualism. Individuals with independent self-construal have more self-efficacy than individuals with interdependent self-construal (Dowd, 2013, Kiuci, 2006). It is mentioned that self-efficacy and emotion regulation strategies have relation to social anxiety. People who have high self-efficacy will have lower level of social anxiety than those with low self-efficacy. In addition, the use of emotion regulation of suppression strategy will further enhance the level of social anxiety. In contrast, the use of cognitive reappraisal strategy will decrease the level of social anxiety.

Based on the description above, self-construal in addition to being related to social anxiety is also corelated to selfefficacy and emotion regulation strategies. Meanwhile, selfefficacy and emotion regulation strategies are corelated to social anxiety. Several studies to examine the correlation of these

factors have been conducted in the other countries, but have not yet in Indonesia. Therefore, the purpose of this study is to examine the interrelationship between these factors with focus on college students from collectivist communities (Indonesia). It will also be seen the degree of level of social anxiety and which self-construal, interdependent or dependent, is more developed in them.

The results of this study are expected to be used as a reference for designing social anxiety model based on selfconstrual, self-efficacy, and emotion regulation strategy as cultural-factors which can then be used as a basis for designing interventions. This study is a preliminary study from the main research that is building a model of social anxiety on college students based on self-construal.

The hypotheses proposed in this study are 1) the social anxiety level of the college students is high enough. 2) The more developed self-construal in the college students is independent self-construal. 3) There is a correlation between self-construal and social anxiety. The interdependent selfconstrual has a positive correlation with social anxiety (3a), on the contrary, independent self-construal has a negative correlation with social anxiety (3b). 4) There is a relation between self-construal and self-efficacy. Interdependent selfconstrual is negatively correlated with self-efficacy (4a), on the other hand, the independent self-construal is positively correlated with self-efficacy (4b). 5) There is a relation between self-construal and suppression regulation strategy. Interdependent self-construal is positively correlated with suppression (5a), on the contrary, independent self-construal is negatively correlated with suppression (5b). 6) There is a relation between self-construal and cognitive reappraisal strategy, independent self-construal is positively correlated with cognitive reappraisal strategy, 7) There is a relation between self-efficacy and social anxiety. The higher selfefficacy is, the lower of the level of social anxiety would be. The last, 8) there is a relation between emotion regulation strategy and social anxiety. People using suppression strategy will experience more social anxiety (8a). Conversely, people who use cognitive reappraisal strategy, will have less social anxiety (8b).

\section{METHODOLOGY}

This research is a quantitative-survey study with different and correlational test analysis techniques. The subjects of the study are 116 undergraduate college students. The instruments used for data collection are Social Anxiety Questionnaire for Adulthood (SAQ-A30), Singelis Self-Construal Scale (SCS), General Self-Efficacy (GSE), and Emotion Regulation Questionnaire (ERQ) that already translated in Indonesian.

SAQ-A30 is a Social Anxiety Scale composed by Caballo, Salazar, Irurtia, Arias and their Research Team in 2012. This instrument consists of 30 items with a response scale of 1 (very low) - 7 (very high). The higher the total score indicates the higher the level of social anxiety. The result of the item discrimination and scale reliability in this study indicate the item of $0.304-0.670$, and Cronbach's Alpha reliability of 0.740 .

SCS is a scale compiled by Singelis (1994) to measure selfconstrual. This scale contains two sub-scales; a sub-scale that measures the interdependent self-construal with 15 number of items, and a sub-scale that measures independent self-construal with 15 number of items. The response scale moves from 1 (strongly disagree) till 7 (strongly agree). Each subject will get two scores namely interdependent self-construal score and independent self-construal score. The result of the item discrimination test for the interdependent sub-scale indicates the item of $0.309-618$, and Cronbach's Alpha reliability of 0.704. As for the independent sub-scale, the items move from 0.322 - 0.539, and Cronbach's Alpha reliability of 0.705 .

GSE is a scale compiled by Schwarzer and Jerusalem (1995) measuring the level of individual self-efficacy in general. This scale contains 10 items with a response scale of 1 (not completely true) - 4 (very true). The higher the total score of the subject is, the higher the level of efficacy would be. The result of the item discrimination test indicates the item of $0.489-0.714$, and Cronbach's Alpha reliability of 0.757 . 
ERQ is a scale compiled by Gross and John (2003) to measure emotion regulation strategy. Similar to self-construal scales, this scale consists of two sub-scales; a sub-scale to measure suppression strategy and sub-scales for measuring cognitive reappraisal strategy. Each subject will get two scores; a score for suppression and a score for cognitive reappraisal. The results of the item discrimination test for the suppression sub-scale show the item of 0.586 - 0.773, and Cronbach's Alpha reliability of 0.768 . As for the sub-scale of cognitive reappraisal, the item moves from $0.348-0.760$, and Cronbach's Alpha's reliability is 0.765 .

\section{RESULTS}

Table 1 presents a description of the level of.social anxiety, self-construal, self efficacy and emotion regulation strategies of the subjects.

Table 1 Description of the level of social anxiety, self-construal, selfefficacy and emotion regulation strategies

\begin{tabular}{|c|c|c|c|c|c|}
\hline & & $\overline{\mathrm{N}}$ & $\begin{array}{l}\text { The } \\
\text { oretical } \\
\text { mean }\end{array}$ & $\begin{array}{l}\text { Empi } \\
\text { rical } \\
\text { mean }\end{array}$ & $\bar{D}$ \\
\hline Social anxiety & 6 & 11 & 90 & 94,4 & 16,235 \\
\hline $\begin{array}{l}\text { Interdependent } \\
\text { self-construal }\end{array}$ & 6 & 11 & 60 & 56,7 & 6,723 \\
\hline $\begin{array}{l}\text { Independent self- } \\
\text { construal }\end{array}$ & 6 & 11 & 60 & 58,6 & 6,643 \\
\hline Self-efficacy & 6 & 11 & 25 & 28,8 & 5,737 \\
\hline $\begin{array}{l}\text { Suppression } \\
\text { strategy }\end{array}$ & 6 & 11 & 16 & 18,2 & 4,552 \\
\hline $\begin{array}{l}\text { Cognitive } \\
\text { reappraisal strategy }\end{array}$ & 6 & 11 & 24 & 32,6 & 6,397 \\
\hline
\end{tabular}

Based on Table 1, the empirical mean of subjects on aspects of social anxiety, self-efficacy and emotion regulation strategies (both suppression and cognitive reappraisal) are higher than the theoretical mean. This indicates that the college students have a high enough level of social anxiety even though their level of efficacy is quite good. As seen from the use of emotion regulation strategies, many subjects are using two strategies of both suppression and cognitive reappraisal. While in the self-construal aspect, although the subject has two characteristics of self-construal namely interdependence and independence, these characteristics are not too prominent.

To make conclusion whether the difference mean in empirical and theoretical values on the social anxiety aspect is meaningful (to test the 1st hypothesis), there is t-test results in Table 2. Similarly, to conclude whether the difference of selfconstrual value of interdependence and independence is meaningful, there will be done with $t$ test. The results of the analysis listed in Table 2 are to answer hypothesis 1 . While the results are listed in Table 3 to test hypothesis 2.

\begin{tabular}{lcllll}
\multicolumn{6}{c}{ Table 2 Different test results of social anxiety level } \\
\hline & $\mathrm{N}$ & $\begin{array}{l}\text { Mean } \\
\mathrm{g}\end{array}$ & $\begin{array}{l}\text { Standard } \\
\text { deviation }\end{array}$ & $\mathrm{t}$ & $\begin{array}{l}\text { Significance } \\
(\mathrm{p})\end{array}$ \\
\hline Empirical & 16 & 94,44 & 16,235 & 2,735 & 0,007
\end{tabular}

Theoretical

$16 \quad 90$

Based on Table 2, the difference mean of empirical and theoretical of social anxiety is very significant $(\mathrm{t}=2.735 ; \mathrm{p}$ $<0.01$ ). Therefore, it can be concluded that the level of social anxiety of the research subjects (in this case the college students) is high enough. Thus, the first hypothesis of this study is accepted. Table 3 will present the results of the analysis to test the second hypothesis.
Table 3 The results of the self-construal t-test

\begin{tabular}{lllll}
\hline Mean & $\begin{array}{l}\text { Std. } \\
\text { deviation }\end{array}$ & t & $\begin{array}{l}\text { Significanc } \\
\text { e (p) }\end{array}$
\end{tabular}

\begin{tabular}{lccccc}
\hline $\begin{array}{l}\text { Interdependent } \\
\text { self-construal }\end{array}$ & 116 & 56,70 & 6,723 & $-2,145$ & 0,034 \\
$\begin{array}{l}\text { Independent self- } \\
\text { construal }\end{array}$ & 116 & 58,66 & 6,643 & & \\
\end{tabular}

From Table 3, the difference mean of interdependent selfconstrual with independence is said to be significant with $\mathrm{t}=$ 2.145 ( $\mathrm{p}<0.05)$. By looking at the mean value, the college students are more likely to develop independent self-construal than the interdependent self-construal. Thus, the second hypothesis of this study, i.e. the more developed self-construal of college students is independent self-construal, is accepted. Furthermore, the results of correlation analysis between variables or aspects to test the third to 8eighth hypothesis are available in Table 4.

Based on Table 4, the accepted hypothesis are: 1) hypothesis $3 \mathrm{a}$ which states there is a positive correlation between interdependent self-construal with social anxiety $(\mathrm{r}=$ $0.253 ; \mathrm{p}<0.05) ; 2$ ), hypothesis $4 \mathrm{~b}$ which states there is a positive correlation between independent self-construal with self-efficacy $(r=0.232 ; \mathrm{p}<0.05)$, And 3 ) hypothesis 6 which states there is a positive correlation of independent selfconstrual with a cognitive reappraisal strategy $(r=0.248 ; p$ $<0.05)$.

The hypothesis that there is a negative correlation between independent self-construal with social anxiety (hypothesis $3 b$ ) and suppression (hypothesis 5a), although the direction of correlation has been shown as being hypothezed, but the value is not significant enough to be unacceptable. Similarly, the hypothesis that there is a negative correlation of self-efficacy with social anxiety (hypothesis 7), a positive correlation of suppression with social anxiety (hypothesis $8 \mathrm{a}$ ), and negative correlation of cognitive reappraisal with social anxiety (8b), although the correlation direction is hypothesized, but the value is insignificant and, therefore, unacceptable. 


\begin{tabular}{|c|c|c|c|c|c|c|c|}
\hline & $\begin{array}{l}\begin{array}{l}\text { Interdependent } \\
\text { construal }\end{array} \\
\text { self- }\end{array}$ & $\begin{array}{l}\text { Independent } \\
\text { construal }\end{array}$ & self- & Self-efficacy & Suppression & $\begin{array}{l}\text { Cognitive } \\
\text { reappraisal }\end{array}$ & Social anxiety \\
\hline $\begin{array}{l}\text { Interdependent self- } \\
\text { construal }\end{array}$ & 1 & 0,065 & & 0,010 & 0,111 & 0,163 & $0,253^{*}$ \\
\hline $\begin{array}{l}\text { Independent } \\
\text { construal }\end{array}$ & & 1 & & $0,232 *$ & 0,107 & $0,248^{*}$ & $-0,27$ \\
\hline Self-efficacy & & & & 1 & & & $-0,196$ \\
\hline Suppression & & & & & 1 & & 0,066 \\
\hline Cognitive reappraisal & & & & & & 1 & $-0,134$ \\
\hline Social anxiety & & & & & & & \\
\hline
\end{tabular}

Table 4. Correlation between self-construal, self-efficacy, emotion regulation strategy and social anxiety

\section{DISCUSSION}

High enough level of social anxiety on the research subject (college students) is actually already predicted. This is because college students are very closely related to performance situations (speaking in front of people, conveying ideas/thoughts, evaluation situations) and situations of social interaction (interacting with new people as well as authoritative figures such as lecturers) which is potentially cause the emergence of social anxiety. From several studies that have been conducted by researchers in previous years (Suryaningrum, 2006, 2016), Hasibuan et al, (2015), and Vriends et al. (2013), it showed the same result that social anxiety among Indonesian college students tend to be at high level.

High cases of social anxiety among Indonesian college students is also influenced by cultural factors. Indonesia is categorized as a collectivist society in which collectivist culture emphasizes the values of cautiousness, harmonizes with mind-feeling-and actions of others, and emphasizes harmony of relationships (Hofmann, Asnaani, \& Hinton, 2010). Therefore, in behaving and interacting with others, Indonesian students try to keep so as not to cause disparity for others. This can ultimately lead to anxieties in situations when dealing or interacting with others for afraid to make mistakes or offending others.

The possible influence of this collectivist cultural background is also reinforced by the results of this study which show a positive correlation of interdependent self-construal with social anxiety. Self-construal is acultural factor that applies at the individual level (Matsumoto \& Juang, 2013). The person who further develops interdependent self-construal more internalizes the cultural values of collectivism. It is therefore possible that college students who develop interdependent self-construal will be more susceptible to social anxiety.

On the research subjects, the more developed self-construal is independent self-construal. This is actually not surprising because as college students, they are required to be independent, initiative, courageous expression, and achievement oriented. These characteristics are the cultivation of cultural values of individualism. For them, the values of individualist cultures seem more suitable for their adoption as an effort to meet the demands. As college students, they are very easy to access and get the influence of other cultural values because of the rapid technology and information flow. These findings suggest that not always people living in collectivist cultures will further develop interdependent self-construal as conceptualized by Markus and Kitayama (1991).

Other results indicate that there is a positive correlation between independent self-construal with self-efficacy and cognitive reappraisal strategy in relation with the underlying theoretical concepts and some previous researches by Konnonovas \& Dallas (2009); Dowd (2013); Matsumoto, Yoo, \& Nakagawa (2008). It seems that the correlation applies universally to all cultural backgrounds. College students with independent self-construal further internalize the values of individualist cultures. It is, therefore, not surprising to positively correlate with self-efficacy. Because people with independent self-construal who are self-sufficient, freeexpression, and oriented to success and achievement will have an effect on their beliefs in dealing with a situation/challenge. The stronger the characteristics of its independence is, the higher the level of self-efficacy would be.

In terms of emotion regulation strategies, for people with independent self-construal, the expression of feeling is selfaffirmation, self-identity, and self-authenticity. College students with independent self-construal will frankly express emotions in harmony with what they feel. The cognitive reappraisal regulation strategy will bridge between what is felt with their expression (Mesquita, Leersnyder, \& Albert, 2014) so that there is no gap (Eng, 2012). Meanwhile, when using a suppression, they would interfere with their self-concept because it must be covered up which means that it is not suitable between what is felt and want to be expressed (Eng, 2012).

In addition to the above description, there is an interesting feature of the findings presented in Table 4. The negative correlation of independent self-construal with social anxiety (although its value is not significant) is probably due to college students who develop independent self-construal more than self-efficacy $(\mathrm{r}=0.232 ; \mathrm{P}<0.05)$ and the emotion regulation strategy used was cognitive reappraisal $(r=0.248$; $p<0.05)$. Meanwhile, based on theoretical concepts and research results, self-efficacy and the use of cognitive reappraisal strategy can reduce the level of social anxiety (Ebrahim, 2008; Fitzgerald, 2012; Hsu et al., 2012; Iancu et al., 2015; Maini, 2010; Tahmassian and Moghadam, 2011; Tarkhan et al., 2013; Thomasson and Psouni, 2010; Min, Yu, Lee, \& Chae, 2013; Ziv et al., 2013). In this study, the correlation of self-efficacy with social anxiety, although not significant, resulted $(\mathrm{r}=$ $0.196)$ as well as cognitive reappraisal strategy $(r=-0.134)$. From these, it can be deduced that in college students with independent self-construal, self-efficacy and cognitive 
reappraisal may be factors that mediate the independent selfconstrual with low social anxiety. This conjecture needs to be proven by further research.

\section{CONCLUSIONS AND RECOMMENDATIONS}

The conclusions of this study are; 1) social anxiety level of the college students is high enough, 2) the more developed selfconstrual in the college students is independent self-construal, 3 ) there is a positive correlation between interdependent selfconstrual with social anxiety, 4) positive correlation between independent self-construal and self-efficacy, 5) there is a positive correlation between independent self-construal and cognitive reappraisal strategy. The study also found that selfefficacy and cognitive reappraisal may be factors that mediate the independent self-construal with low social anxiety. However, further research still needs to be conducted to prove it and become useful to be used as a basis for building social anxiety model based on self-construal college students and its intervention.

\section{REFERENCES}

American Psychiatric Association. (2013). Diagnostic and statistical manual of mental disorders (5th ed.). Washington, DC: American Psychiatric Association.

Antony, M.M., \& Swinson, R.P. (2008). Shyness \& social anxiety workbook. Second edition. Canada: New Harbinger Publications, Inc

Butler, E.G., Lee, T.L., \& Gross, J.J. (2007). Emotion regulation and culture: Are the social consequences of emotion supression culture-specific?. Emotion, 7(1), 30 - 48 .

De Leersnyder, J., Boiger, M., \& Mesquita, B. (2013). Cultural regulation of emotion: individual, realtional, and structural sources. Frontiers in Psychology, 4 (55), 1 - 11.

De Leersnyder, J., Boiger, M., \& Mesquita, B. (2013). Cultural regulation of emotion: individual, realtional, and structural sources. Frontiers in Psychology, 4 (55), 1 - 11.

Dowd, S. (2013). The relationship between self-perception and external factors: Self-efficacy and self-construal. Thesis. Baruch College of the City University of New York.

Ebrahim, M. (2008). Self-efficacy and social phobia: evaluation of Bandura's social cognitive model. Psychological Studies, 4(3), $115-127$.

Eng, J.S. (2012). Emotion regulation and culture: The effects of cultural models of self on Western and East Asian Differences in supression and reappraisal. UC Berkeley Electronic Thesis and Dissertations.

Essau, C.A., Leung, P.W., Conradt, J., Cheng, H., \& Wong, T. (2008). Anxiety symptoms in Chines and German adolescents: Their relationship with early learning experiences, perfectionism, and learning motivation. Depression and Anxiety, 25 (9), 801 - 810.

Fitzgerald, N. (2012).The relationship between self-efficacy, social anxiety, personality types and strong anxious reactionism in a non-clinical sample of undergraduate students. Dublin Business School. Retrieved May 20, 2014, from DBS eSource.

Hasibuan, E.P.N., Srisayekti, W., \& Moeliono, M.F. (2015). Gambaran kecemasan sosial berdasarkan Liebowitz Social Anxiety Scale (LSAS) pada remaja akhir di Bandung. Jurnal Publikasi Berkala Penelitian Pascasarjana Universitas Padjajaran, 1 - 10.

Heinrichs, N., Rapee, R.M., Alden, L.A., Bogels, S., Hofmann, S.G.,Oh, K.J., \& Sakano, Y. (2006). Cultural differences in perceived social norms and social anxiety. Behavior Research and Therapy, 44, $1187-1197$.

Henderson, L., Gilbert, P., \& Zimbardo, P. (2014). Shyness, social anxiety, and social anxiety disorder. Dalam S.G. Hofman \& P.M. DiBartolo (Eds.), Social anxiety. Clinical, development, and social perspectives (3rd ed.) (hlm.95 - 115). USA: Elsevier Inc.

Hofmann, S.G., Asnaani, A., \& Hinton, D.E. (2010). Cultural aspects in social anxiety and social anxiety disorder. Depression and Anxiety, 27 (12), 1117 - 1127.
Hong, J.J., \& Woody, S.R. (2007). Cultural mediators of self-reported social anxiety. Behavior Research and Therapy, 45(8), $1779-$ 1789.

Ho. L.Y.,\& Lau, A.S. (2011). Do self-report measures of social anxiety reflect cultural bias or real difficulties for asian american college students?. Cultural Diversity and Ethnic Minority Psychology. 17 (1), 52 - 58

Hsu, L., Woody, S.R., Lee, H.-J., Peng, Y., Zhou, X., \& Ryder, A.G. (2012). Social anxiety among East Asians in North America: East Asian socialization or the challenge of acculturation? Cultural Diversity and Ethnic Minority Psychology, 18 (2), 181 $-191$

Iancu, I., Bodner, E., Ben-Zion, I.Z. (2015). Self esteem, dependency, self-efficacy and self-criticism ini social anxiety disorder. Comprehensive Psychiatry, 58, 165 - 171.

Kiuchi, A. (2006). Independent and interdependent self-construals: Remifications for a multicultural society. Japanese Psychological Reserach, 48(1), 1 -16.

Kononovas, K., \& Dallas,T. (2009). A cross cultural comparisson of perceived stress and self-efficacy across Japanesse, U.S. and Lithuanian students. Psychologija, 39, 59- 70.

Lee, M.R., Okazaki, S., \& Yoo, H.C. (2006). Frequency and intensity of social anxiety in Asian Americans and European Americans. Cultural Diversity and Ethnic Minority Psychology, 12(2), 291 $-305$

Levinson, C.A., Langer, J.K., \& Rodebaugh, T.L. (2011). Selfconstrual and social anxiety: Considering personality. Personality and Individual Differences, 51(3), 355 - 359

Levpuscek, M.P. \& Berce, J. (2012). Social anxiety, social acceptance and academic self-perceptions in high-school students. Drus. Istraz. Zagreb God, 2 (116), 405 - 419

Maini, K. (2010). The influence of self-presentational efficacy on men's social anxiety in the weight room. Electronic Theses and Dissertations, Paper 265. University of Windsor.

Markus, H.R., \& Kitayama, S. (1991). Culture and the self: Implications for cognition, emotion, and motivation. Psychological Review, 98 (2), 224 - 253.

Markus, H.R., \& Kitayama, S. (2010). Culture and selves: A cycle of mutual constitution. Perspectives on Psychological Science , 5 (4), 420- 430 .

Matsumoto, D. (2006). Are cultural differences in emotion regulation mediated by personality traits?. Journal of Cross Cultural Psychology, 37(4), $421-437$.

Matsumoto, D., Yoo, S.H., Nakagawa, S., 37 Mambers of Multinational Study of Cultural Display Rules. (2008). Culture, emotion regulation, and adjustment. Journal of Personality and Social Psychology, 94(6), 925 - 937.

Matsumoto, D., \& Juang, L. (2013). Culture, self, and identity. Culture \& Psychology. 5th edition. California: Wadsworth, Cengage Leraning.

McNeil, D.W., \& Randall, C.L. (2014). Conceptualizing and describing social anxiety and its disorders. Dalam S.G. Hofman \& P.M. DiBartolo, (Eds.), Social anxiety. Clinical, development, and social perspectives (3rd ed.) (hlm. 3 - 26). USA: Elsevier Inc.

Mesa, F., Beidel, D.C., \& Bunnel, B.E. (2014). An examination of psychopathology and daily impairment in adolescents with social anxiety disorder. PloS One 9(4): e93668. doi:10.1371/journal.pone.0093668

Mesquita, B., Leersnyder, J.D., \& Albert, D. (2014). The cultural regulation of emotions. Dalam J.J. Gross (Ed.), Handbook of emotion regulation ( 2 nd ed.) (hal. $284-301)$. New York: The Guildford Press.

Min, J.- A., Yu, J.J., Lee,C.- U., Chae, J,-H. (2013). Cognitive emotion regulation strategies contributing to resilience in patiens with depression and/or anxiety disorders. Comprehensive Psychiatry, $54,1190-1197$

Miyamoto, Y., \& Ma, X. (2013). Dampening or savoring positive emotions: a dialectical cultural script guides emotion regulation. Emotion, 1 - 46. doi: 10.1037/a0025135.

Moscovitch, D.A., Hofmann, S.G., \& Litz, B.T. (2005). The impact of self-construals on social anxiety: a gender-specific interaction. Personality and Individual Differences, 38, 659- 672.

Norasakkunkit, V., Kitayama, S., \& Uchida, Y. (2013). Social anxiety and holistic cognition: self-focused social anxiety in the united 
states and other-focused social anxiety in Japan. Journal of Cross-Cultural Psychology, 43 (5),742 - 757.

Nordstrom, A.H., Goguen, L.M.S., \& Hiester, M. (2014). The effect of social anxiety and self-esteem on college adjustment, academics, and retention. Journal of College Counseling, (17), $48-63$.

Park, I.J.K., Sulaiman, C., Schwartz, S.J., Kim, S.Y., Ham, L.S., Zamboanga, B.L. (2011). Self-construal and social anxiety among Asian American college students: Testing emotion supression as a mediator. Asian American Journal of Psychology, 2(1), $39-50$.

Pina, A.A., Little, M., Wynee, H., \& Beidel, D.C. Assesing social anxiety in african american youth using the social phobia and anxiety inventory for children. (2014). Journal Abnormal Child Psychology, 42, 311 - 320.

Schreier, S.-S., Heinrichs, N., Alden, L., Rapee, R.M., Hofmann, S.G., Chen, J.,...Bogels, S.(2010). Social anxiety and social norms in individualistic and collectivistic countries. Depression and Anxiety, 27 (12), $1128-1134$.

Suryaningrum, C. (2006). Indikasi gangguan kecemasan pada mahasiswa Fakultas Psikologi Universitas Muhammadiyah Malang. Naskah tidak dipublikasikan, Lembaga Penelitian Universitas Muhammadiyah, Malang.

Suryaningrum, C. (2016). Kecemasan sosial mahasiswa: Studi pendahuluan. Disampaikan pada kegiatan Seminar Nasional "Riset-Riset Terkini di Bidang Ilmu Perilaku" pada 26 November 2016, Universitas Gadjah Mada, Yogyakarta.

Tahmassian, K., \& Moghadam, N.J. (2011). Relationship between self-efficacy and symptoms of anxiety, depression, worry and social avoidance in a normal sample of students. Iran Journal Psychiatry Behavior Sciences, 5(2), 91 - 98.

Tarkhan, M., Esmaeilpour, M., \& Tizdast, T. (2013).A study of the relationship between social anxiety, social self-efficacy and body image in the girl students of the Islamic Azad University at Tonekabon Branch. Europian Online Journal of Natural and Social Sciences, 2 (4), $510-515$.

Thomasson, P., \& Psouni, E. (2010). Social anxiety and related social impairment are linked to self-efficacy and dysfunctional coping. Scandinavian Journal Psychology, 51(2), 171 - 178.

Topham, P., \& Russel, G. (2012, April 4). Social anxiety in higher education. The Psychologist, 25, 280-282.

Vriends, N., Pfaltz, M.C., Novianti, P., \& Hadiyono, J. (2013). Taijin kyofusho and social anxiety and their clinical relevance in Indonesia and Switzerland. Frontiers in Psychology, 4(3), 1-9.

Woody, S.R., Miao, S., Kellman-McFarlane, K. (2015). Cultural differences in social anxiety: Ameta-analysis of asian and European heritage samples. Asian American Journal of Psychology, (1), 47 - 55.

Zhu, X., Yao, S., Dere, Y., Zhou., B., Yang, J., \& Ryder, A.G. (2014). The cultural shaping of social anxiety:Concerns about causing distress to others in Han Chinese and Euro-Canadian outpatients. Journal of Social \& Clinical Psychology, 33, $906-$ 917.

Ziv, M., Goldin, P.R., Jazaieri, H., Hahn, K.S., \& Gross, J.J. (2013). Emotion regulation in social anxiety disorder: behavioral and neural responses to three socio-emotional tasks. Biology of Mood \& Anxiety Disorders, 3(20), 1 - 17. 